\title{
Medicinal Plants
}


Proceedings of an International Symposium Cosponsored by the Morris Arboretum of the University of Pennsylvania and the World Health Organization, Philadelphia, Pennsylvania, April 1993 


\section{Medicinal Plants}

Their Role in Health and Biodiversity

Edited by Timothy R. Tomlinson and Olayiwola Akerele

\section{$\overline{\text { PENN }}$}

University of Pennsylvania Press

Philadelphia 
Copyright (C) 1998 Morris Arboretum

All rights reserved

109876544321

Published by

University of Pennsylvania Press

Philadelphia, Pennsylvania 19104

Library of Congress Cataloging-in-Publication Data

Medicinal plants : their role in health and biodiversity / edited by

Timothy R. Tomlinson and Olayiwola Akerele.

p. $\mathbf{c m}$.

"Proceedings of an international symposium cosponsored by the Morris Arboretum of the University of Pennsylvania and the World Health Organization, Philadelphia, Pennsylvania, April 1993" - CIP t.p. verso.

Includes bibliographical references and index.

ISBN 0-8122-3431-6 (cloth : alk. paper)

1. Materia medica, Vegetable-Congresses. 2. Medicinal plantsCongresses. 3. Botany, Medical-Congresses. I. Tomlinson,

Timothy R. II. Akerele, Olayiwola.

RS164.M373 1998

$615^{\prime} .32-\mathrm{dc} 21$ 